\title{
CAMINHOS PARA A SELEÇÃO DA NOMINATA DE UM DICIONÁRIO DE FALSOS AMIGOS
}

\author{
PATHWAYS FOR THE SELECTION OF THE ENTRIES FOR \\ A DICTIONARY OF FALSE FRIENDS
}

\author{
Adja Balbino de Amorim Barbieri Durão \\ Docente do Programa de Pós-Graduação em Linguística - UFSC \\ Docente do Programa de Pós-Graduação em Estudos da Tradução - UFSC \\ Bolsista de Produtividade do CNPQ \\ Reinhold Werner ${ }^{1}$ \\ Docente da Universität Augusburg
}

\section{Resumo}

Neste texto, por um lado, Durão e Werner propõem que falsos amigos são tanto os pares lemáticos interlinguísticos fonológica ou morfologicamente iguais ou parecidos, os quais, compartilhando ou não o mesmo étimo, discrepam em pelo menos uma de suas acepções, como os pares lemáticos que têm divergências estruturais, ortográficas e de gênero entre uma língua e outra. Por outro lado, centram a sua atenção na pertinência de tomar dados procedentes de análises contrastivas e de análises de erros linguísticos sistemáticos cometidos por estudantes brasileiros de espanhol como base para a elaboração de um dicionário de falsos amigos (português-espanhol), que se destina, prioritariamente, a falantes da variante brasileira de português que sejam estudantes de espanhol como língua estrangeira ou professores deste idioma.

Palavras-chave: Lexicografia. Transferência linguística. Falsos amigos.

\begin{abstract}
In this text, on the one hand, Durão and Werner propose that false friends refer both to the interlinguistic lemmatic pairs phonologic or morphologically equal or similar, which, partaking or not the same etymon, disagree in at least one of its significations, and to the lemmatic pairs which have structural, orthographic and genre divergences between one language and the other. On the other hand, they focus their attention on the importance of taking data proceeding from contrastive analyses and from the analyses of the systematic linguistic errors produced by learners of the languages concerned as a

\footnotetext{
1 Professor do Lehrstuhl für Angewandte Sprachwissenschaft (Romanistik) / Universität Augsburg. Werner integrou a equipe que coordenou a elaboração dos seguintes dicionários: Nuevo Diccionario de Americanismos - Tomo I - Nuevo Diccionario de Colombianismos. Santafé de Bogotá: Instituto Caro y Cuervo, 1993; Nuevo Diccionario de Americanismos - Tomo III - Nuevo Diccionario de Argentinismos. Santafé de Bogotá: Instituto Caro y Cuervo, 1993; Nuevo Diccionario de Americanismos - Tomo III Nuevo Diccionario de Uruguayismos. Santafé de Bogotá: Instituto Caro y Cuervo, 1993; Diccionario del Español de Cuba - Español de Cuba / Español de España. Madrid: Gredos, 2000; Diccionario del Español de Argentina - Español de Argentina / Español de España. Madrid: Gredos, 2000.
} 
foundation for the elaboration of a dictionary of false friends (DiFAPE). Such a dictionary is foremost addressed to speakers of Brazilian Portuguese who are students of Spanish as a foreign language or teachers of that language.

Key-words: Lexicography. Crosslinguistc influence. False friends.

\section{INTRODUÇÃO}

Quando, em 1928, Koessler e Derocquigny propuseram a denominação faux amis, eles fizeram referência a pares de lexias que compartilhavam uma etimologia comum, mas significados, no todo ou em parte, diferentes. Vinay e Darbelnet ([1958] 1977) reempregaram essa denominação, mantendo a mesma concepção proposta por aqueles linguistas franceses. Entretanto, quando Chuquet e Paillard se apropriaram dela (CHUQUET; PAILLARD, 1987), o aspecto etimológico foi deixado de lado. A partir de então, aqueles que a têm empregado oscilam entre fazer referência a pares de lexias iguais ou parecidas de duas línguas diferentes que têm raízes etimológicas em comum e a pares de lexias iguais ou parecidas que não têm parentesco etimológico algum, embora, nos dois casos, tenham significados, no todo ou em parte, diversos.

No Brasil, a denominação falsos amigos tem sido associada àquelas palavras de duas línguas que se assemelham em seu aspecto formal, mas que se diferenciam, em maior ou menor medida, em seu aspecto semântico, tenham tais palavras raízes etimológicas em comum ou não.

No que se refere ao par de línguas português-espanhol, essa denominação se firmou principalmente sobre o trabalho de Nascentes (1943), que elaborou glossários que se disseminaram de forma abrangente nesse país e, ao longo dos anos, foram-se tornando referência nesse campo tão escasso de pesquisa. Nascentes (1943) reforçou a noção de que falsos amigos são "palavras semelhantes com significados diferentes". Do mesmo modo, Becker ([1969] 1988), ao elaborar um manual didático que serviu como instrumento de ensino e aprendizagem de espanhol para várias gerações de estudantes brasileiros, conseguiu, em suas mais de 75 reimpressões, não apenas alastrar os termos heterossemântico, heterogenérico e heteroprosódico, mas também reforçar a noção de que a denominação falsos amigos faz referência a palavras de duas línguas, formalmente parecidas, mas que têm algum tipo de divergência semântica.

Neste texto, com base em discussões desencadeadas nos trabalhos de Haensch (1956), Wandruska (1977) e Gottlieb (1984), apresenta-se uma proposta de falsos amigos, segundo a qual estes são tanto pares lemáticos, fonológica ou morfologicamente iguais ou parecidos, os quais, compartilhando ou não um mesmo étimo, discrepam em pelo menos uma de suas acepções, como pares lemáticos que apresentam divergências ortográficas, de gênero e de regência.

\section{UM DICIONÁRIO DE FALSOS AMIGOS NA MEDIDA DAS NECESSIDADES DE APRENDIZES BRASILEIROS DE ESPANHOL}


De acordo com Bugueño Miranda (2003, p. 105), a história dos dicionários de falsos amigos começou seu percurso em 1747, quando Eleázar de Mauvillon elaborou um primeiro trabalho lexicográfico desta natureza, que foi, na sequência, cultivado principalmente por franceses, alemães, ingleses e, a partir de 1980, conforme informa Bugueño Miranda com base em Gorbahn-Orme e Hausmann (2003, p. 105), também por espanhóis. No Brasil, essa tradição além de recente, não chegou a configurar-se plenamente, pelo menos não na esfera científica, havendo, até o momento, uma presença bastante reduzida deste tipo de repertório lexicográfico entre as obras dicionarísticas. Neste país, a maior parte dos dicionários de falsos amigos disponíveis no mercado no eixo espanhol-português, pelo menos até onde pudemos averiguar, tem sido produzidas por leigos que, tendo passado temporadas em países hispanofalantes, acabam por transformar suas anotações pessoais (sobre palavras do espanhol em comparação com o léxico do português) em glossários / "dicionários", os quais, na quase totalidade dos casos encontrados, são publicados por editoras de pouca tradição na área. Veja-se, por exemplo, o caso dos dicionários de falsos amigos de Bello e Bath (1996), de Mariano (1999), de Marzano (2002), de Bosco Monte (2003) e de Fornari (2004). Na apresentação do dicionário de Mello e Bath (1999), encontra-se a seguinte explicação:

Thiago Mello (...) tem grande familiaridade com a língua espanhola (...), pois viveu muitos anos na Bolívia e no Chile. (...) Essa experiência fez com que reunisse uma ampla coleção de peculiaridades da língua de Cervantes, que nesta obra compartilha com o leitor. (...)

Sérgio Bath (...) nos últimos anos, tem se dedicado à caça de "falsos amigos" do francês, do italiano, do latim e do alemão, além do espanhol, numa série que reúne particularidades vocabulares dessas línguas.

De forma similar, na introdução do dicionário de Marzano (2002), lê-se:

(...) comecei a escrever este dicionário em 1994, quando cheguei à Espanha. Durante anos, colecionara anotações sobre as falsas semelhanças, mas era algo que fazia de modo irregular e sem intenção definida. Ao chegar à Espanha, porém, percebi que se quisesse falar realmente bem o castelhano, teria de eliminar minhas dúvidas e equívocos sobre essas incômodas palavrinhas que parecem dizer uma coisa mas dizem outra com significado diferente ou até mesmo oposto. (...) Daí surgiu a idéia do dicionário (...) que apresento com orgulho, não apenas por ser fruto de longas - porém divertidas - horas de trabalho, mas também porque tenho certeza de que ele contribuirá definitivamente para preencher esta lacuna (...) 
O campo dos dicionários de falsos amigos entre o português e o espanhol na esfera científica, com raríssimas exceções, ainda é uma lacuna a ser preenchida.

\section{O QUE CARACTERIZA O DiFAPE?}

Tomando os dicionários de falsos amigos identificados no mercado editorial brasileiro como objeto de análise, Durão (2009) constatou que todos pretendem ser obras polifuncionais e reúnem pares léxicos interlinguais, fonológica ou morfologicamente iguais ou parecidos, que apresentam divergências em pelo menos uma de suas acepções (tenham essas lexias a mesma origem etimológica ou não). ${ }^{2}$

Como se sabe, ainda que o desenvolvimento histórico das línguas das quais nos ocupamos nesta proposta (português e espanhol) tenha muitos pontos de contato, as categorias lingüísticas de cada uma delas são elaborações próprias de cada cultura, diante do que ressaltamos que, embora haja numerosas unidades léxicas no português às quais correspondam unidades léxicas homógrafas no espanhol, cujos significados coincidem totalmente (por exemplo, sala / sala, vestido / vestido, etc.), que haja unidades cujos significados podem ser inferidos com pouco esforço (por exemplo, comunicação / comunicación, também / también, etc.) e, que haja unidades léxicas cujos sentidos emergem de simples associações (por exemplo, árvore / árbol, nas / en las, etc.), naturalmente, há unidades linguísticas que dependem de conhecimento específico, porque, embora existam nas duas línguas, suas acepções só coincidem parcialmente (por exemplo, embaraçada / embarazada ${ }^{3}$, etc.). Além disso, existem unidades cuja forma só consta em uma dessas línguas (por exemplo, palito de fósforo / cerilla, etc.) e outras que expressam funções mediante formas diferentes, como, por exemplo, os particípios do português e os particípios do espanhol. Os particípios dos verbos regulares são, em sua maioria, idênticos nas duas línguas, entretanto há também casos nos quais o particípio é regular em português e irregular no espanhol (como absolver / absolver, cujas formas são, respectivamente, absolvido / absuelto), assim como casos nos quais o particípio é irregular no português e regular no espanhol (como pagar / pagar, cujos particípios são, respectivamente, pago / pagado) (DURÃO; WERNER, 2007).

As diferenças no modo como as unidades léxicas do espanhol e do português são empregadas podem-se dar nas suas formas (ou seja, no modo como soam, como são pronunciadas ou como são escritas), nas suas estruturas internas (isto é, nas partes que se unem às formas para conformar os seus significados), nos seus significados (ou seja, na forma como as unidades são usadas para expressar seus significados), nos seus conceitos (isto é, nos itens que podem fazer referência a esses conceitos), nas suas associações (ou seja, as outras unidades que podem substituídas), nos seus usos (ou seja,

\footnotetext{
${ }^{2}$ Não retomaremos, aqui, as noções de falsos amigos parciais e falsos amigos totais propostas por Wandruska (1977), mas as assumimos como pressuposto.

3 Port. Embaraçado: Adj. 1. atrapalhado; constrangido; 2. emaranhado; 3. atrapalhado; confuso; 4. embaralhado; enredado. (Borba, org. 2004). / Esp. Embarazada: p. p. de embarazar*. 2. adj. Dícese de la mujer preñada. (*embarazar: del ár. bāraza, oponerse, cortar el paso. con el pref. en) tr. Impedir, estorbar, retardar una cosa. 2. Dejar encinta a una mujer. 3. prnl. Quedarse embarazada una mujer. 4. Quedar impedido con cualquier embarazo (RAE, 1992).
} 
nas estruturas nas quais podem aparecer), nas suas colocações (isto é, as palavras ou tipos de palavras com as quais podem aparecer) e nas suas restrições de uso (isto é, onde e com que freqüência, tais palavras podem ser empregadas). Tais contingências podem fazer com que produzir um texto em espanhol, tendo o português como língua materna, não seja uma tarefa necessariamente simples (DURÃO; WERNER, 2007).

A proposta de Durão e Werner $(2007)^{4}$ de elaborar um dicionário de falsos amigos na direção português-espanhol (DiFAPE), como qualquer outro dicionário, pretende oferecer a estudantes brasileiros de espanhol que serão professores dessa língua uma fonte de consulta e, ao mesmo tempo, uma ferramenta pedagógica que destaque os contrastes existentes entre essas línguas. Os destinatários potenciais desse dicionário são, principalmente, falantes nativos da variante brasileira de português que estão vinculados a cursos de Licenciatura em Letras - Espanhol, que, por terem essa língua materna e por estudarem um idioma tipologicamente próximo ao seu, têm necessidades claramente diferenciadas se comparados a aprendizes que estudam essa mesma língua, mas têm línguas nativas diferentes do português. Daí Durão e Werner pretenderem refletir a premissa mencionada, qual seja a intenção de reunir tanto pares lemáticos, fonológica ou morfologicamente iguais ou parecidos, os quais, compartilhando ou não um mesmo étimo, discrepem em pelo menos uma de suas acepções, como pares lemáticos que apresentem divergências ortográficas, de gênero e de regência, seguindo a direção língua materna dos prováveis consulentes - português $\rightarrow$ língua estrangeira objeto de estudos - espanhol.

Embora o foco de atenção deste trabalho seja apresentar os caminhos seguidos para a seleção das unidades léxicas que estão sendo lematizadas no DiFAPE, quer-se ressaltar que o princípio norteador do DiFAPE, não apenas no que concerne à seleção dos lemas, como também à constituição da macroestrutura e, ainda, à elaboração da informação microestrutural, é o contraste linguístico. Por isso, sua base científica são princípios da Metalexicografia aliados a pressupostos da Lingüística Contrastiva, por permitirem entrever os tipos de dificuldades a que os possíveis usuários do dicionário precisarão fazer frente nas mais diversas situações produtivas em que venham a se envolver, por via do contraste entre os dois sistemas linguísticos em questão.

\section{BASE DE CONSTITUIÇÃO DA NOMINATA DO DiFAPE}

Ao iniciar a caminhada para a seleção da nominata do DiFAPE, Durão e Werner mapearam o vocabulário presente em 13 livros didáticos espanhóis elaborados entre

\footnotetext{
4 Durão e Werner são autores de um macroprojeto de pesquisa que se intitula Dicionários Contrastivos Português-Espanhol (DiCoPoEs) e que conta com subsídios do CNPq, obtidos mediante o Edital MCT/CNPq 15/2007 (Universal - Faixa A), da Fundação Araucária (governo do Estado do Paraná), por meio do Edital de Apoio à Pesquisa Básica e Aplicada 14/2008 e do DAAD-CAPES, através do Programa de Intercâmbio Científico de Curta Duração (2011). Esta macropesquisa abriga o subprojeto intitulado Parâmetros para a elaboração de um dicionário de falsos amigos na direção português-espanhol, desenvolvido sob a coordenação de Durão junto ao Departamento de Línguas e Literaturas Estrangeiras da Universidade Federal de Santa Catarina.
} 
2001 e $2003^{5}$, que abrangiam diversas disciplinas, a saber: língua e literatura espanhola, biologia, geologia, meio ambiente, ética, história, geografia, música e educação plástica e visual. O mapeamento desses livros permitiu que se elaborasse a lista $\mathrm{I}^{6}$.

Em um segundo momento, tomou-se como fonte de dados a parte referente ao léxico/vocabulário de sete coleções de livros didáticos para ensino de espanhol a brasileiros amplamente usadas no Brasil ${ }^{7}$ e elaboradas entre 2004 e 2011, tanto em ensino oficial como em cursos livres $^{8}$. Considerando-se que as unidades léxicas identificadas nesses materiais, supostamente, correspondiam àquelas que equivalem ao nível básico de conhecimento de vocabulário dessa língua, elas foram incluídas em uma base de dados do projeto.

Na sequência, cruzou-se a lista I com a lista II, primeiramente eliminando as unidades léxicas que não coincidiam. A seguir, aquelas unidades léxicas que não apresentavam aspectos contrastivos entre o espanhol e o português foram deixadas de lado, chegandose, desse modo, à lista III (ou o lemário provisório do DiFAPE).

Desse lemário provisório foram selecionadas algumas unidades léxicas consideradas prototípicas no contexto do conjunto, uma vez que, teoricamente, em conjunto, essa tipologia seria a que viria a constituir o lemário do DiFAPE. Essas unidades léxicas prototípicas se caracterizavam por ter:

1. prefixos diferentes (exemplo: desumano / inhumano)

2. sufixos diferentes: -dade / -dad, -tad; -idão / -itud; -eiro, -eira / -ero, -a; -iço, -a / icio, -a; -me / -mbre; -vel / -ble, etc. (exemplos: lealdade / lealtad; multidão / multitud; cume / cumbre)

3. diferença de tonicidade (Exemplo: democracia /demokra'sia/ / democracia /demo'krasia/)

4. diferença de gênero (Exemplo: a análise / el análisis)

5. diferenças semânticas (Exemplo: apelido / apellido - sobrenome / sobrenombre)

6. diferenças ortográficas (língua / lengua);

\footnotetext{
${ }^{5}$ Nas buscas feitas nesses livros didáticos, selecionaram-se as palavras presentes nos textos de leitura e foram deixadas de lado as palavras utilizadas nos apêndices teóricos e nos exercícios.

${ }^{6}$ As referências desses livros didáticos encontram-se no anexo 1.

${ }^{7}$ Deve-se esclarecer que, a maior parte dos livros didáticos para ensino de espanhol usados no Brasil, adotam o espanhol standard como base de trabalho, dando às demais variantes do espanhol, modestos espaços nos quais são oferecidas notas marginais e assistemáticas, e, naturalmente, essa preferência incide nas palavras reunidas no DiFAPE, daí, também, nossa opção por livros didáticos produzidos na Espanha para a elaboração da Lista 1.

${ }^{8}$ As referências desses livros didáticos encontram-se no anexo 2.
} 
7. duas formas em português e uma forma em espanhol (Exemplos: cavaleiro cavalheiro / caballero; cozinha - fogão / cocina; povo - povoado / pueblo; sono sonho / sueño)

8. duas formas em espanhol e uma forma em português (Exemplos: abertura / abertura - apertura; bacia / bacía - cuenca; criar / criar - crear; exploração / exploración explotación)

9. não permitir deduzir os equivalentes mediante regras filológicas de correspondência regular (Exemplo: requerimento / solicitud);

10. diferenças de regime (Exemplo: ir de avião / ir en avión)

11. diferenças de colocação (Exemplo: preto e branco / blanco y negro)

Várias unidades léxicas prototípicas dessa seleção foram usadas como base para a elaboração de atividades a serem desenvolvidas por estudantes universitários de espanhol de diferentes níveis de conhecimento do idioma. Essas unidades eram apresentadas aos sujeitos da pesquisa em português, solicitando-se que fossem passadas para o espanhol. Uma vez traduzidas, essas unidades serviam como pretexto para a elaboração de enunciados nessa língua. O propósito dessas atividades era validar o lemário provisório. Mediante os resultados das análises de erros sistemáticos cometidos pelos sujeitos envolvidos na parte empírica desse estudo, algumas unidades léxicas do lemário provisório foram respaldadas, outras não previstas inicialmente foram incorporadas e, ainda, outras foram eliminadas.

As análises de erros praticadas caracterizaram-se por ser pseudolongitudinais e abrangeram dois anos letivos (2010-2011). Os dados foram coletados em amostras específicas, que incidiram na produção de aprendizes (29 estudantes matriculados na disciplina Língua Espanhola III no primeiro semestre de 2010; 25 estudantes matriculados na disciplina Língua Espanhola VII no segundo semestre de 2010; 30 estudantes matriculados na disciplina Língua Espanhola VI no segundo semestre de 2011; 11 estudantes matriculados na disciplina Língua Espanhola IV no segundo semestre de 2011). As coletas refletiram tanto usos relativamente espontâneos da língua, como usos elicitados. Os tipos de elicitação praticados foram a elicitação clínica, considerando que os estudantes produziram dados de natureza variada mediante a redação de textos de gêneros diversos, e a elicitação por meio de métodos experimentais, já que foram submetidos a instrumentos específicos para a elicitação de dados, os quais continham os itens linguísticos que queríamos pesquisar (DURÃO [1999] 2004).

Considerou-se erro tanto a forma que foi chamada por Corder (1971) de erro superficial, isto é, aquela na qual o erro que está claramente visível em um enunciado, como a que foi chamado por este autor de erro subjacente, isto é, aquela forma errônea que, embora não esteja claramente visível na superfície do enunciado, torna a mensagem inadequada para uma situação linguística determinada. Cada erro analisado foi submetido a dois tipos de interpretação: a interpretação normal, que deriva da 
atribuição do significado do enunciado por parte do pesquisador com base nas regras da língua, e a interpretação plausível, que deriva do fato de o pesquisador interpretar o enunciado por sua própria ótica, levando em conta, primeiramente, a LM do sujeito e, em segundo lugar, o contexto no qual a produção foi realizada.

Depois de perpassar o lemário provisório pelo crivo das análises de erros praticadas com os sujeitos antes descritos, este foi examinado pelo filtro da competência linguística dos redatores do dicionário, constituindo, por fim, a nominata do DiFAPE.

\section{CONCLUSÃO}

Muitos estudiosos vêm tentando demonstrar que certas tendências que aprendizes brasileiros de espanhol (incluindo os de nível avançado) e tradutores brasileiros manifestam com frequência, tais como fazer traduções literais, espanholizando as unidades lingüísticas do português, e usar unidades léxicas do português no contexto do espanhol sem modificá-las ou modificando apenas alguns de seus componentes, são frequentes demais para serem desprezadas (BENEDETTI, 1992; DURÃO, [1999] 2004; TORIJANO PÉREZ, 2003). O fato é que, ainda que a proximidade tipológica existente entre o português e o espanhol propicie grande transparência interlinguística, essa transparência, em alguns casos, é flagrantemente enganosa, criando situações de opacidade que, embora não costumem obstaculizar totalmente os processos intercomunicativos, dificultam-nos sobremaneira. Em algumas dessas situações, os protagonistas são os falsos amigos, diante do que se pode afirmar contundentemente que um dicionário bilíngue contrastivo português-espanhol não é apenas bem-vindo como ferramenta pedagógica, é uma necessidade.

\section{REFERÊNCIAS}

MELlO, T.; BATH, S. Amigos traiçoeiros: coletânea de falsos amigos e outras peculiaridades da língua espanhola para uso dos brasileiros. Brasília: Editora Universidade de Brasília, 1996.

BECKER, Idel. Manual de Español. Gramática y ejercicios de aplicación. Lecturas. Correspondencia. Vocabularios. Antología poética. 75a. ed., São Paulo: Nobel, [1969]1988. 
BENEDETTI, Ana Mariza. Interferencias morfosintácticas y semánticas del portugués en el aprendizaje del español. Madrid: Tesis de doctorado. Universidad Complutense de Madrid, 1992.

BOSCO MONTE, João. Dicionário ilustrado: falsas semelhanças espanhol-português. Ceará: Didáticos, 2003.

BUGUEÑO MIRANDA, Felix. Consideraciones para un nuevo diccionario de falsos amigos español-portugués. Polifonia, Cuiabá, n.6, p.103-127, 2003.

CHUQUET, H.; PAILLARD, M. Approche linguistique des problèmes de traduction anglais-français. Paris: Orphys, 1987.

DURÃO, A. B. de A. B. Análisis de errores en la interlengua de brasileños aprendices de español y de españoles aprendices de portugués. Londrina: Eduel, [1999] 2004.

Por detrás de la transparencia existe una opacidad! La lectura por estudiantes brasileños de textos redactados en español. Anuario brasileño de estudios hispánicos. Brasília, n.12, p.13-28, 2002.

. Os bastidores de um dicionário de falsos amigos na direção portuguêsespanhol. Boletim: revista da área de humanas, Londrina, n. 56, p. 9-26, 2009.

; WERNER, R. Dicionário Contrastivo Português-Espanhol (DiCoPoEs). Projeto de Pesquisa aprovado pelo Conselho Nacional de Desenvolvimento Científico e Tecnológico. Edital MCT/CNPq 15/2007 - Universal.

FORNARI, C. Minidicionário Antiportunhol. Conheça melhor o espanhol. Rio de Janeiro: Axcel Books do Brasil, 2004.

GOTTLIEB, K. H. "Grundprinzipien eines Wörterburchr der falschen freunde des übersetzers". Ein Beitrag zur praktischen lexicographie. Studien nur neuhochdeutschen Lexicographie, 5: 103-134, 1984.

HAENSCH, G. "Faux Amis". bzw keinen lexicon der Faux Amis. Lebende Sprachen 1: $1,1956$.

KOESSLER, M.; DEROCQUIGNY, J. Le faux amis ou les trahisons du vocabulaire anglais. 2 ed. Paris: Librairie Vuibert, 1957.

MARIANO, G. ¡Muy amigo! Um guia de espanhol para escapar das armadilhas do portunhol. Rio de Janeiro: DIFEL, 1999.

MARZANO, F. Como não ficar embarazado em espanhol. Dicionário EspanholPortuguês de falsas semelhanças. Rio de Janeiro: Campus / Elsevier, 2002.

NASCENTES, A. Gramática da língua espanhola para uso dos brasileiros. 5 ed. São Paulo: Companhia Editora Nacional, 1943. 
TORIJANO PÉREZ, José Agustín. Análisis teórico-práctico de los errores gramaticales en el aprendizaje del español, L2: expresión escrita. Salamanca. Tese Doctoral. Universidad de Salamanca, 2003.

VINAY, J. P.; DARBELNET, J. Stylistique comparée du français et de l'anglais. Nouvelle édition augmentée et corrigée. Paris: Didier, [1958] 1977.

WANDRUSKA, M. "Falsche Freunde": ein linguistisches Problem und seine Lösung. Zeitschrift für franzözische Sprache und Literatur, 5: 53-77, 1977.

\section{ANEXO 1}

1. BLASCO, Pilar; GÁlVEZ, Juan; GONZÁLEZ, Alejandro; MATEOS, Esperanza; MULAS, $M^{a}$ Luisa; SÁNCHEZ, Rosa. Lengua Castellana y Literatura. $2^{\circ}$ curso de Educación Secundaria Obligatoria. Madrid: McGraw Hill, 2002.

2. BLASCO, Pilar; GÁlVEZ, Juan; GONZÁLEZ, Alejandro; MATEOS, Esperanza; MULAS, M ${ }^{\text {a }}$. Luisa; SÁNCHEZ, Rosa. Lengua Castellana y Literatura. $4^{\circ}$ curso de Educación Secundaria Obligatoria. Madrid: McGraw Hill, 2002.

3. BRUSI, David; AGUILERA, Luis Miguel; CHAVES, Fernando; VIVES, Francisco; MAJADAS, Arturo. Biología y Geología. $4^{\circ}$ ciclo de Educación Secundaria Obligatoria. Madrid: Santillana, 2003.

4. CAPELLÁN, Jesús; ARRANZ, Jesús. Lengua Castellana y Literatura. $1^{\mathrm{er}}$ curso de Educación Secundaria Obligatoria. Madrid: McGraw Hill, 2002.

5. CAPELLÁN, Jesús. ARRANZ, Jesús; MELGAR, Casimiro; GÁlVEZ, Juan. Lengua Castellana y Literatura. $3^{\text {er }}$ curso de Educación Secundaria Obligatoria. Madrid: McGraw Hill, 2002.

6. CASAJUANA, R.; CRUELlS, E.; ESCALES, T.; GARCÍA, M.; GATELL, C.; CARRERA, M.; MOLINERO, F. Medio Natural, social y cultural. Castilla y León. Tercer ciclo de la Educación Primaria Obligatoria. Madrid: Vicens Vives, 2001.

7. CORTINA, Adela; DOMENÉ, Ma Begoña; GARCÍA, Domingo; MARTÍNEZ, Emilio; ROS, Juan Manuel; SMILG, Norberto. Ética. $4^{\circ}$ curso de Educación Secundaria Obligatoria. Madrid: Santillana Educación, 2003.

8. DÍAZ RUBIANO, Manuel; FERNÁNDEZ ARMIJO, Ma . Isabel; JIMÉNEZ MAQUEDA, Manuel Adolfo; DEL PINO GARCÍA, Felipe José. Historia. Ciencias Sociales. $4^{\circ}$ curso de Educación Secundaria Obligatoria. Madrid: Oxford Educación, 2003.

9. FENOLLOSA, R.; REIG, I; ROCA, S.; SANZ, J. M. Música. $1^{\text {er }}$ ciclo de Educación Secundaria Obligatoria. Madrid: Hermes Editora General, 2002.

10. GARCÍA ALMIÑANA, E.; GOMIS LLORCA, J. P.; GONZÁLEZ SALCEDO, J.; GREGORIO LÓPEZ-RUIZ, J. M.; LATORRE NUÉVALOS, F; PARCERO TORRE, C.; RAMÍREZ ALEDÓN, G.; SEBASTIÁN VICENT, R. Geografía e Historia. $2^{\circ}$ ciclo de Educación Secundaria Obligatoria. Madrid: ECIR Editorial, 2003. 
11. GRANDA GALLEGO, Cristina; HERNÁNDEZ HERNÁNDEZ, Carlos; JOVER GÓMEZ-FERRER, María; NÚÑEZ HERAS, Raúl. Geografía. Ciencias Sociales. $3^{\text {er }}$ ciclo de Educación Secundaria Obligatoria. Madrid: Oxford Educación, 2002.

12. GÓMEZ GIL, Ricardo; VALVUENA PRADILLO, Rafael. Matemáticas. $2^{\circ}$ ciclo de Educación Secundaria Obligatoria. Madrid: SM, 2001.

13. HURTADO, Miguel; PLATÓN, Vicente. Educación plástica y visual. $2^{\circ}$ ciclo de Educación Secundaria Obligatoria. Madrid: ECIR Editorial, 2002.

14. PASTOR, Andrea; RUIZ, Francisco; VALBUENA, Mercedes; VALVERDE, Jesús Ángel. Conocimiento del Medio, Castilla y León. $5^{\circ}$ curso de Educación Primaria. Madrid: Ediciones SM, 2001.

15. RODICIO, Emilio Casares. Música. $2^{\circ}$ ciclo de Educación Secundaria Obligatoria. León: Editora Everest, 2002.

16. VIVES, Francisco; CHAVES, Fernando; CEREZO, José Manuel. Biología y Geología. $3^{\text {er }}$ ciclo de Educación Secundaria Obligatoria. Madrid: Santillana, 2003.

\section{ANEXO 2}

1. ARTUÑEDO, Belén; DONSON, Cynthia. !Adelante!: Comunicación en español. vol. 7. São Paulo: FTD, 2002.

2. ..'Adelante!: Comunicación en español. vol. 8. São Paulo: FTD, 2002.

3. BOROBIO, Virgilio. !Adelante!: Comunicación en español. vol. 5. São Paulo: FTD, 2002. . !Adelante!: Comunicación en español. v. 6. São Paulo: FTD, 2002.

4. BRIONES, Ana Isabel; FLAVIAN, Eugenia; FERNÁNDEZ, Gretel Eres. Español Ahora. vol. 1. São Paulo: Moderna, 2003.

5. . Español ahora. vol. 2. São Paulo: Moderna, 2003.

6. . Español ahora. vol. 3. São Paulo: Moderna, 2003.

7. CALLEGARI, Marília Vasques; RINALDI, Simone. !Arriba!. v.1. São Paulo: Moderna, 2004.

8 . . !Arriba!. v.2. São Paulo: Moderna, 2004.

9. DÍAZ, Rafael Fernández; HERRERO, María Antonieta Andión. Curso de español para hablantes de portugués: superior 1. Madrid: Arco/Libros, 2001.

10. DURÃO; Adja Balbino de Amorim Barbieri; ALONSO, María Cibele Pelizzari. Curso de español para hablantes de portugués: básico 1. Madrid: Arco/ Libros, 2001.

11. Curso de español para hablantes de portugués: básico 2.

Madrid: Arco/ Libros, 2001. 
12. DURÃO; Adja Balbino de Amorim Barbieri; SILVA, Maria Eugênia Olímpio de Oliveira. Curso de español para hablantes de portugues: avanzado 1. Madrid: Arco/ Libros, 2001.

13. Arco/ Libros, 2001.

. Curso de español para hablantes de portugués: avanzado 2. Madrid:

14. GARCÍA, María de los Ángeles; HERNÁNDEZ, Josephine Sánchez. Español sin fronteras: curso de lengua extranjera. vol. 1. São Paulo: Scipione, 2002.

15.

Scipione, 2002.

. Español sin fronteras: curso de lengua extranjera. vol. 2. São Paulo:

16.

Scipione, 2002.

. Español sin fronteras: curso de lengua extranjera. vol. 3. São Paulo:

17.

Scipione, 2002.

. Español sin fronteras: curso de lengua extranjera. vol. 4. São Paulo:

18. GONZÁLEZ, Jesús Fernández; MOZOS, Emilio Prieto de los. Español para todos. vol. 1. São Paulo: Ática / Universidad de Salamanca, 2003.

19. Salamanca, 2003.

Español para todos. vol. 2. São Paulo: Ática / Universidad de

20. Español para todos. vol. 3. São Paulo: Ática / Universidad de Salamanca, 2003.

21. Español Para Todos. vol. 4. São Paulo: Ática / Universidad de Salamanca., 2003.

22. MARTIN, Ivan Rodrigues. Espanhol Série Brasil. São Paulo: Ática, 2004.

23. NOVICK, Beatriz; OSUNA, Miriam. !Arriba!. vol. 4. São Paulo: Moderna, 2004.

24. ROMANOS; JACIRA. Espanhol Expansión: ensino médio. São Paulo: FTD, 2004.

25. SUÁREZ, Freddy Rodríguez; RODRÍGUEZ, Ginger de la Torre. !Arriba! vol. 3. São Paulo: Moderna, 2004. 